\title{
Levels of physical activity and sleep patterns among older people with dementia living in long-term care facilities: A 24-hour snapshot
}

\author{
Wendy Moyle ${ }^{\mathrm{a}, \mathrm{b} *}$, Cindy Jones ${ }^{\mathrm{a}, \mathrm{b}}$, Jenny Murfield ${ }^{\mathrm{a}}$, Brian Draper ${ }^{\mathrm{c}}$, Elizabeth Beattie ${ }^{\mathrm{d}}$, \\ David Shum $^{\mathrm{a}, \mathrm{e}}$, Lukman Thalib , Siobhan O’Dwyer ${ }^{\mathrm{a}, \mathrm{g}}$, Cindy M. Mervin ${ }^{\mathrm{a}, \mathrm{h}}$
}

${ }^{a}$ Menzies Health Institute QLD, Griffith University, Nathan, Brisbane, Queensland, Australia

${ }^{\mathrm{b}}$ School of Nursing and Midwifery, Nathan Campus, Griffith University, Nathan, Brisbane, Queensland, Australia

'School of Psychiatry, University of New South Wales, Sydney, Australia

${ }^{\mathrm{d}}$ School of Nursing, Queensland University of Technology, Kelvin Grove, Brisbane, Queensland, Australia

${ }^{\mathrm{e}}$ School of Applied Psychology, Mt Gravatt Campus, Griffith University, Brisbane, Queensland, Australia

f Department of Public Health, College of Health Sciences, Qatar University, Qatar ${ }^{\mathrm{g}}$ Medical School, University of Exeter, Exeter, United Kingdom

${ }^{\mathrm{h}}$ Centre for Applied Health Economics, School of Medicine, Nathan Campus, Griffith University, Nathan, Brisbane, Queensland, Australia

*Corresponding author: Professor Wendy Moyle, Menzies Health Institute QLD, Griffith University, 2.10 Health Sciences (N48), 170 Kessels Road, Nathan, Brisbane, Queensland, 4111, Australia. Tel: +61 73735 5526; Fax: +61 73735 5431; w.moyle@griffith.edu.au 


\begin{abstract}
Objectives: To objectively measure the daytime and nighttime levels of physical activity and sleep patterns of older people with dementia living in long-term care facilities over a 24-hour period.
\end{abstract}

Study design: Nested within a larger research program, this cross-sectional study involved 415 residents, aged $\geq 60$ years, with a documented diagnosis of dementia, from 28 long-term care facilities in South-East Queensland, Australia.

Main outcome measures: Residents wore SenseWear® activity armbands continuously for 24-hours, with data recorded for: step count; total energy expenditure; metabolic equivalent of task (MET); and the amount of time spent physically active, lying down, awake and asleep. Residents' levels of cognitive impairment (Rowland Universal Dementia Assessment Scale), agitation (Cohen-Mansfield Agitation Inventory-Short Form), and demographic data were also collected.

Results: From a total of 415 residents monitored with the SenseWear® activity armbands, 192 residents met the valid wear-time of 21 hours or more, and had activity and sleep data recorded. These residents were largely inactive during the daytime (engaged in an average of 1.8 hours of light physical activity), but achieved recommended amounts of sleep at night (average of 6.8 hours). There was considerable variation within the sample, and activity and sleep differed by sex $(p<.001)$, age $(p=.010)$, mobility $(p<.001)$, and antipsychotic usage $(p=.030)$.

Conclusions: These data can be used by long-term care clinicians to assist in planning interventions and care approaches, which promote physical activity and good sleep practices, and are individualized to physical and cognitive capabilities.

Australian New Zealand Clinical Trials Registry (ACTRN12614000508673). 
Key words: Activity monitor; Cognitive impairment; Cross-sectional; Long-term care; Older adults; SenseWear ${ }^{\circledR}$.

\section{Highlights}

- LTC residents with dementia were largely inactive, yet did not sleep excessively.

- There was considerable variability in levels of activity and sleep over 24-hours.

- SenseWear® armbands were not well tolerated in our study.

- Using wearable technology with cognitively impaired individuals is challenging.

- More work is needed in device size, placement, and comfort. 


\section{Introduction}

A significant proportion of all older people living in long-term care (LTC) facilities have dementia, with rates of 50\% reported in Australia [1] and 80\% in the United Kingdom [2]. Residents with dementia typically experience functional physical decline upon admission more so when cognitive impairment is severe [3] - and commonly exhibit sleep difficulties in LTC $[4,5]$. Whilst the cause of physical decline and sleep disruption can vary between residents, a number of factors commonly contribute, including age-related changes, medical conditions and disorders $[4,5]$; adverse side-effects of prescribed psychotropic medication [6]; a focus on resident safety [7]; prolonged periods of daytime napping and time spent in bed [8, 9]; and the noisy, bright, routine-based environment of LTC facilities [10].

Wearable device-based technologies, such as actigraphs, offer an objective and continuous measure of levels of physical activity and sleep patterns. Actigraphy has been used for a number of decades in nighttime sleep research with residents with dementia living in LTC [11]. However, the use of wearable technology for the measurement of daytime sleep is less common [11], as is physical activity, which has been typically measured using observation or interview-based methods. Of the objectively measured studies conducted to date, over a 24-hour period, LTC residents with dementia spend half their total time asleep [9, 12], and do not have one hour where they remain completely awake [12]. On average, residents sleep for between seven to 10 hours at night $[8,9,13]$, and for between three to four hours during the day [9]. As regards to levels of physical activity, residents are sedentary for nearly three-quarters of their time [14], which is consistent with the LTC population generally $[15,16]$.

Physical inactivity and sleep disruption in LTC facilities is detrimental to residents' health $[17,18]$ and, as such, it is important for clinicians to plan interventions and develop appropriate care approaches to address these issues. Given that technology is constantly 
advancing, it is necessary and timely for estimates of activity and sleep levels for this population to be provided when measured by modern wearable technology.

This study aimed to concurrently and objectively measure, using a modern triaxial accelerometer, the daytime and nighttime levels of physical activity and sleep patterns over a 24-hour period in a large sample of LTC residents with dementia. Differences according to resident characteristics were also explored, with the aim of providing specific information to aid the development of more tailored, individualized care approaches.

\section{Methods}

\subsection{Design, sample, and setting}

This cross-sectional study uses secondary outcome data collected at baseline of a larger program of research (a cluster randomised controlled trial) exploring the impact of a therapeutic robotic animal (PARO) on older people with dementia living in LTC [19] Australian New Zealand Clinical Trials Registry (ACTRN12614000508673). Residents $(n=415)$ aged $\geq 60$ years with a documented diagnosis of dementia, were drawn from 28 government approved and accredited LTC facilities, located within a 100km radius of the Brisbane central business district in South-East Queensland, Australia.

Ethical approval was granted by Griffith University Human Ethics Committee (NRS/03/14/HREC) and respective LTC organisations. Personal (if capable) or proxy written informed consent was obtained for all participating residents at enrolment.

\subsection{Data collection}

\subsubsection{Cognitive functioning, level of agitation, and demographic information}

Trained Research Assistants (RAs) collected the following data at baseline of the larger research program, prior to participation in any intervention-related activities: 
1. The Rowland Universal Dementia Assessment Scale (RUDAS) [20] was used to assess residents' severity of cognitive impairment because of its ability to accommodate the cultural and linguistic diversity found in this part of Queensland, and its previously demonstrated good reliability and significant correlation with the Mini Mental State Examination [20]. Covering six domains - memory, visuospatial orientation, praxis, visuoconstructional drawing, judgement, and language - the instrument provides a total score that can range from 0 to 30 . The lower the score, the greater the cognitive impairment, and a score of $\leq 22$ is indicative of possible impairment.

2. The Cohen-Mansfield Agitation Inventory - Short Form (CMAI-SF) [21] was used to assess residents' levels of agitation because of its internationally established use with older people with dementia in LTC [22]. Using a five-point scale - ranging from "never" to "a few times an hour or continuous for half an hour or more" - facility nursing staff rated the frequency that 14 agitated behaviours were displayed by the resident in the previous two-week period. The instrument provides a total score, ranging from 14 to 70 , with higher scores suggestive of greater agitation.

3. A range of resident data were extracted from facility medical records and from discussions with residents, their families, and facility nursing staff (Table 1).

\subsubsection{Activity and sleep data}

Data were collected using the SenseWear ${ }^{\circledR}$ Professional 8.0 activity armband (Temple Healthcare, BodyMedia, Inc). This device was chosen for use with our study population because of its: light-weight design; the inclusion of multiple sensors, including a triaxial accelerometer that processes data by in-built algorithms; on/off body sensors to record weartime; and its validity for use in a number of populations, including older people with dementia in LTC [23], and community-dwelling older adults [24, 25]. 
The following data metrics were of interest in this study: 1) step count (number of steps taken); 2) total energy expenditure (kilojoules); 3) Metabolic Equivalent of Task (MET); and the time spent (hours) 4) in physical activity (hours spent with a MET of $>1.5$ ), 5) lying down, 6) awake, 7) asleep overall, 8) in light sleep, 9) in deep sleep, and 10) in very deep sleep. All variables were predefined by SenseWear ${ }^{\circledR}$ Software based on artificial intelligence, and all data were recorded in 60 second epochs, as is standard for research in the area [e.g., 15, 24].

Between Monday to Saturday, trained RAs placed the SenseWear ${ }^{\circledR}$ armbands on residents' upper non-dominant arm over the triceps muscle. Collecting data from residents on different days of the week counteracts the variability resulting from the absence of contextual data about what the residents were doing at the time of recording (e.g. activity versus inactivity during and across the days in care settings). Residents were asked to wear the armbands continuously for 24-hours, removing only for bathing or discomfort. Nursing and care staff were trained in the placement and removal of the armbands to assist residents.

\subsection{Data processing and analysis}

All SenseWear ${ }^{\circledR}$ data were downloaded using SenseWear ${ }^{\circledR}$ software. Data were reduced into overall (24-hours) and hourly summaries and, following inspection of data and discussions with facility staff regarding residents’ bed-times, daytime (8am-7:59pm) and nighttime (8pm7:59am) summaries. A member of the research team visually checked 10 percent of extracted data against the recorded SenseWear® software for 100 percent accuracy. A valid 'day' was defined as 21 hours or more of data recorded over the 24-hour period, with less wear-time considered too inaccurate for reliable and valid analyses. This cut-off is consistent with a previous study that used the SenseWear ${ }^{\circledR}$ armbands with community-dwelling older adults 
[25]. Using the on/off body-time data, only residents with a valid wear-time of $\geq 21$ hours were included in the analysis.

Using SPSS version 22.0 (IBM Corp. Armonk, NY), demographic variables were compared between included and excluded groups of residents, using Pearson’s Chi-Square or Fisher's Exact Tests (categorical data), and one-way analysis of variance (ANOVAs) (continuous data). SenseWear ${ }^{\circledR}$ variables were examined overall (24-hours), and for daytime (8am-7:59pm) and nighttime (8pm-7:59am). Hourly variation in residents’ activity was explored using a series of one-way within-subjects repeated measures ANOVAs. Means were inspected to explore trends in the data and, where sphericity was violated, the Greenhouse Geisser correction was applied. To examine whether activity levels over the 24-hour period differed according to resident characteristics, a series of multivariate analysis of variance (MANOVAs), with Pillai’s Trace reported, were conducted for each SenseWear® dependent variable and the following categorical variables: 1) sex; 2) mobility status; 3) medication usage (all); 4) antidepressant usage; 5) antipsychotic usage; 6) anxiolytic and hypnotic usage; 7) anticonvulsant usage; 8) anticholinesterase inhibitor usage; 9) analgesic usage; and the following continuous variables recoded into groups 10 ) age (“< $<85$ years”, " $\geq 85$ years”); 11) cognitive impairment (RUDAS score) (“0-9 severe”, “10-17 moderate”, “18-23 mild”); and 12) agitation (CMAI-SF score) (“0-14 never”, “15-28 less than once a week”, “29-42 once or several times a week”, “43-56 once or several times a day”, “57-70 a few times an hour or continuous for half an hour or more”).

\section{Results}

From a total of 415 residents monitored using SenseWear ${ }^{\circledR}$ armbands, 192 met the valid wear-time of 21 hours or more, and had activity and sleep data recorded. Included residents had an average of 23.3 hours ( $\mathrm{SD}=0.8$ ) of available data over the 24-hour period. The 
demographic and clinical profiles of included and excluded residents were largely similar, although there was a significant between-group difference for agitation levels $(F(1,413)=$ 4.320, $p=.038$ ), with included residents less agitated than their counterparts. This difference may not be clinically meaningful, however, as the mean scores of the two groups are within the same response category of 'less than once a week' (28.9 vs. 31.0 respectively) (Table 1).

\section{$3.1 \quad$ Over 24-hours}

Daily activity data showed that, on average, residents took 307.5 steps ( $S D=803.3$ ), expended 6594.6 kilojoules of energy ( $\mathrm{SD}=1436.4)$, and had a MET of 1.1 $(\mathrm{SD}=0.2)$, which is the metabolic equivalent required of sitting. Residents spent approximately $40 \%$ of the 24 -hour period lying down (10.4 hours, SD=4.0), and only $10 \%$ engaged in light physical activity (2.4 hours ( $\mathrm{SD}=2.3$ ), defined as MET of $>1.5-3$ ). There were no instances of moderate or vigorous physical activity. Residents spent nearly two-thirds (63.8\%) of the 24-hour period awake and a third (33.8\%) asleep, with an average 15.3 hours (SD=3.8) of waking time, and 8.1 hours ( $\mathrm{SD}=3.8$ ) of sleeping time recorded. Light sleep accounted for three-quarters (77.8\%) of all sleep-time (6.3 hours; $\mathrm{SD}=3.0)$; residents averaged 1.2 hours $(\mathrm{SD}=1.2)$ of deep sleep, and 0.6 hours ( $\mathrm{SD}=0.8$ ) of very deep sleep over the 24-hour period (Table 2).

\subsection{Daytime}

Between the hours of 8am and 7:59pm, residents averaged 240.2 steps ( $S D=646.7$ ), expended 3557.4 kilojoules of energy ( $\mathrm{SD}=921.4)$, and had a mean MET of $1.2(\mathrm{SD}=0.3)$. Fifteen percent of residents' time during the day was spent lying down (2.0 hours, $\mathrm{SD}=2.3$ ) and in light physical activity (1.8 hours, $\mathrm{SD}=1.8$ ). Residents were awake for the majority of daytime hours (10.2 hours, $\mathrm{SD}=1.8$ ) and asleep for just over $10 \%$ of this time (1.3 hours, $\mathrm{SD}=1.7)$, largely in light sleep (1.0 hours, SD=1.4) (Figures 1-3). 
There was considerable variation in the activity and sleep patterns among daytime hours and, with the exception of step count $(p=.193)$ and deep sleep $(p=.248)$, this was significant for all SenseWear® variables. Overall, residents were most active during the afternoon and into the early evening: step counts were highest from 12-5:59pm, whilst highest averages for total energy expenditure, MET, and time spent in light physical activity were between 3-6:59pm. Further, residents were typically lying down and asleep during three daytime, post-dining periods: morning-time from 8-9:59am; early afternoon from 1-1:59pm; and early evening from 6-7:59pm.

\subsection{Nighttime}

Between the hours of 8pm and 7:59am, residents were largely inactive, with an average of 67.2 steps ( $\mathrm{SD}=199.8), 3037.2$ kilojoules of energy expended (SD=631.4), MET of 1.0 $(S D=0.2)$, and $5 \%$ of time spent in light physical activity ( 0.6 hours, $S D=0.7)$. Although $70 \%$ of nighttime hours were spent lying down (8.4 hours, SD=2.7), residents were only asleep for $56.7 \%$ of the night, with an average of 6.8 hours $(S D=2.9)$ sleep recorded. Light sleep accounted for three-quarters of night sleep-time (5.3 hours; SD=2.3), with residents averaging 1.0 hours ( $\mathrm{SD}=1.1$ ) of deep sleep, and 0.5 hours $(\mathrm{SD}=0.7)$ of very deep sleep (Figures 1-3).

There was significant variation in the activity and sleep patterns of residents among nighttime hours for all variables. Residents were least active between 11pm-4:59am, with averages at their lowest for step count, total energy expended, MET, and time spent in light physical activity. The time residents spent lying down and asleep increased hourly from 8pm until 1:59pm for lying down, and until 12.59pm for sleep, after which hourly averages decreased until 7:59am. Periods of deep and very deep sleep were at their highest between 10pm and 4:49am. 


\subsection{Activity and sleep patterns over 24-hours by resident characteristics}

There were significant differences in the activity and sleep patterns according to: sex $(F[10,181]=6.49, p<.001$; Pillai’s Trace=0.26); age $(F[10,181]=2.43, p=.010$; Pillai’s Trace $=0.12)$; level of mobility $(F[20,350]=3.14, p<.001$; Pillai's Trace $=0.30)$; and prescribed antipsychotic usage $(F[10,181]=2.06, p=.030$; Pillai’s Trace=0.10). Specifically, male residents expended more total energy than female residents $(p<.001)$, and those aged $\geq 85$ years took fewer steps $(p=.034)$, expended less total energy $(p<.001)$, and spent less time in light physical activity ( $p=.021)$ than their younger counterparts. Further, mobile residents took more steps $(p<.001)$, expended more total energy $(p=.001)$, spent more time in light physical activity $(p<.001)$ and with a greater intensity - higher mean MET - $(p=.032)$, and spent less time lying down ( $p=.016)$, than those with limited/no mobility. Finally, residents taking antipsychotic medication had a lower mean MET $(p=.006)$ and were awake less ( $p=.037)$ and asleep more $(p=.048)$, specifically in deep sleep $(p=.029)$, than residents not taking antipsychotics.

No significant differences were found for level of cognitive impairment, level of agitation, medication usage overall, and usage of antidepressants, anxiolytics and hypnotics, anticonvulsants, anticholinesterase inhibitors, and analgesics.

\section{Discussion}

Over a 24-hour period, residents in this study were largely inactive. Whilst the absence of established rates of activity for this population prevents comparison, the general trend of inactivity and high rate of sedentariness is consistent with previous studies conducted with this population specifically [14], and also in LTC generally [15, 16]. Physical activity has the potential to improve the health, well-being, and sleep of older people with dementia. A Function-Focused Care (FFC) philosophy of care may go some way toward achieving this, 
educating care staff on the importance of physical activity, and providing education/mentorship in the ways that activities can be safely introduced into the 'everyday' and tailored to the capabilities of each resident (i.e., person-centered) . The adoption of such an approach has been successfully demonstrated in a cluster randomized controlled trial involving residents with moderate to severe dementia: care staff were able to learn the new approach and change their practice, and residents spent significantly more time in physical activity and function, and fell less often [26]. LTC facilities may also benefit from the inclusion of more formal physical exercise opportunities within their scheduled activities. A recent systematic review [27] reported that the most significant improvements for LTC residents with dementia occurred when activities involved strength, flexibility, balance, and endurance (typically walking), and were conducted for at least 30-minutes twice a week.

Within our results, there was considerable variability in the levels of activity and sleep over 24-hours. Given the different ways in which dementia symptomatically presents, this is likely to be reflective of the heterogeneity of this population, and reinforces the need to offer a person-centred approach to activity planning. Further variation was also noted according to residents' sex, age, level of mobility, and use of prescribed antipsychotic usage. Similar to previous research conducted in LTC [15], male residents were found to expend significantly more total energy than female residents, whilst older residents and those less mobile were generally less active. The finding that residents taking antipsychotics slept more and also had lower mean MET, serves to highlight the sedative effect that such medication can have on this already sedentary population.

Consistent with rates reported in studies with the general LTC population [15, 16], residents in the current study were physically active for just $15 \%$ of their daytime hours. Most of this activity occurred during the afternoon and into the early evening, principally from 36:59pm. This increase in activity could be representative of heightened agitation levels during 
these times and may be possible evidence of 'sundowning', or rather the perception of it by facility staff, with the activity during this time noticeably higher than the low levels observed at other times of the day. Nevertheless, the trend towards increased activity during the afternoon may suggest that LTC could benefit from changes in staffing levels according to activity levels.

Residents got an average of approximately seven hours of sleep, which is consistent with previous Australian research [13] and the recommended 7-8 hours required for older adults [28]. The low levels of daytime napping observed in our study (10\%) - which is much lower than the $\sim 30 \%$ reported previously [8] - may have contributed to the levels of sleep achieved. However, we also found that from around 1-2am, the amount of time residents spent asleep and lying down decreased hourly until daytime began. Whilst increased nighttime awakenings are a hallmark of dementia, routine toileting/continence care practices may also account for some of the sleep disturbance, with over-night checks shown to occur in Australian LTC facilities routinely [29]. Facilities should consider auditing their current nighttime continence care practices, and align when and how they check residents based on individual factors [29].

SenseWear ${ }^{\circledR}$ armbands were not well tolerated in our study, with just over half (53.7\%) of all residents not meeting the set valid wear-time criteria of $\geq 21$ hours. This rate is higher than that reported in previous studies conducted with people with dementia, whereby non-adherence rates of approximately one-third were observed [30]. The inclusion of a large sample - 415 residents from 28 long-term care facilities and with varying levels of cognitive impairment - may have contributed to the higher rate of non-adherence we observed. Our findings and experiences during the study highlight the challenge of using wearable technology with cognitively impaired individuals and supports, more broadly, the need for 
more work in this area, particularly regarding practical issues such as device size, placement, and comfort [31].

Study limitations include: 1) Residents wore SenseWear ${ }^{\circledR}$ armbands for one continuous 24-hour period only. 2) We set the valid wear-time at $\geq 21$ hours, which was used in a previous study using the armbands with community-dwelling older adults [25]. A different cut-off may have produced different results, although the high wear-time in our study (average of 23.3 hours) supports the validity of the data captured. 3) Daytime (8am7:59pm) and nighttime (8pm - 7:59pm) periods were defined based on discussions with LTC staff regarding usual bed-times and inspection of data. Whilst this cut-off is supported by research that has shown that the average bedtime for a LTC resident is 20:30 [32], the results may not be fully reflective of individual waking and sleeping periods. 4) This study reports objectively measured data, and offers no insight into what the residents were doing over the 24-hour period. 5) The SenseWear ${ }^{\circledR}$ activity armbands have been shown to both under- and over-estimate step counts in young adults in controlled and free-living conditions [33]. Readers should be mindful of the limitations of this technology when interpreting our findings.

\section{Conclusions and implications for Practice}

The findings present an overall picture of general daytime inactivity but acceptable amounts of sleep at night, although there was considerable variation within the sample, specifically according to sex, age, mobility status, and antipsychotic usage. These objectively collected data can be used by clinicians to plan interventions and care approaches that promote physical activity and good sleep practices, which are individualized to physical and cognitive capabilities. Our findings suggest that LTC facilities may specifically benefit from the inclusion of more formal physical exercise opportunities within their scheduled activities, and 
from a function-focused approach to care. Further, facilities should give consideration to varying staffing according to activity levels (perhaps more staff should work in the afternoon when the likelihood of agitated activity levels are highest), and to auditing nighttime continence care practices based on individual resident factors.

\section{Acknowledgments}

Thanks are expressed to all aged care organisations, facilities, care staff, residents, and families who so generously took part in the research. Thanks are also expressed to the following study personnel for their assistance with: project management and cluster leadership - Dr Marguerite Bramble, Dr Jasmin Grayson-Collins and Amanda McNiven; and extraction of SenseWear ${ }^{\circledR}$ data - Billy Sung and Gloria Cheng.

\section{Conflict of interest}

Wendy Moyle was personally loaned equipment (5 Paros) for the duration of the larger study by the developer, Dr. Takanori Shibata. Dr Shibata provided no monetary support for the study, and had no role in any aspect of the study design, undertaking, analysis, and interpretation, or in the reporting of the findings and preparation of the manuscript. All other authors declare no financial, personal, or potential conflicts of interest.

\section{Author contributions}

Wendy Moyle conceived and designed the larger study, in consultation and review with Cindy Jones, Brian Draper, Elizabeth Beattie, David Shum, Lukman Thalib, Siobhan O’Dwyer, and Cindy Mervin. Wendy Moyle and Cindy Jones oversaw the data collection, and Jenny Murfield and Cindy Jones led the analysis and interpretation of data. Wendy 
Moyle, Cindy Jones, and Jenny Murfield prepared a draft manuscript, and all authors provided comment/revision and approval of the final version.

\section{Funding}

This work was supported by the Australian Government National Health and Medical

Research Council [1065320]. The funders had no role in any aspect of the study design, collection, analysis, and interpretation of data, reporting of findings, manuscript preparation, or the decision to submit the article for publication. 


\section{References}

[1] Australian Institute of Health and Welfare, Residential aged care in australia 2010-11: A statistical overview. Cat. No. Age 68., AIHW, Canberra, 2012.

[2] On behalf of Alzheimer's Society, M. Prince, M. Knapp, M. Guerchet, P. McCrone, M. Prina, A. Comas-Herrera, R. Wittenberg, B. Adelaja, B. Hu, D. King, A. Rehill, D. Salimkumar, Dementia uk: Update, Alzheimer's Society, 2014.

[3] A.S. Helvik, K. Engedal, J.S. Benth, G. Selbaek, A 52 month follow-up of functional decline in nursing home residents - degree of dementia contributes, BMC Geriatr. 14 (2014) 45.

[4] J.L. Martin, S. Ancoli-Israel, Sleep disturbances in long-term care, Clin. Geriatr. Med. 24 (1) (2008) 39-vi.

[5] A.L. Gordon, J.R. Gladman, Sleep in care homes, Rev. Clin. Gerontol. 20 (04) (2010) 309-316.

[6] M. Gustafsson, U. Isaksson, S. Karlsson, P.O. Sandman, H. Lovheim, Behavioral and psychological symptoms and psychotropic drugs among people with cognitive impairment in nursing homes in 2007 and 2013, Eur. J. Clin. Pharmacol. 72 (8) (2016) 987-994.

[7] E.M. Galik, B. Resnick, I. Pretzer-Aboff, 'Knowing what makes them tick': Motivating cognitively impaired older adults to participate in restorative care, Int. J. Nurs. Pract. 15 (2009) 48-55.

[8] J.L. Martin, A.P. Webber, T. Alam, J.O. Harker, K.R. Josephson, C.A. Alessi, Daytime sleeping, sleep disturbance, and circadian rhythms in the nursing home, Am. J. Geriatr. Psychiatry 14 (2) (2006) 121-129.

[9] A. Fetveit, B. Bjorvatn, Sleep duration during the 24-hour day is associated with the severity of dementia in nursing home patients, Int. J. Geriatr. Psychiatry 21 (10) (2006) 945950. 
[10] J.F. Schnelle, P.A. Cruise, C.A. Alessi, K. Ludlow, N.R. al-Samarrai, J.G. Ouslander, Sleep hygiene in physically dependent nursing home residents: Behavioral and environmental intervention implications, Sleep 21 (5) (1998) 515-523.

[11] J.L. Martin, A.D. Hakim, Wrist actigraphy, Chest 139 (6) (2011) 1514-1527.

[12] D. Jacobs, S. Ancoli-Israel, L. Parker, D.F. Kripke, Twenty-four-hour sleep-wake patterns in a nursing home population, Psychol. Aging 4 (3) (1989) 352.

[13] D.T. Brown, J.L. Westbury, B. Schuz, Sleep and agitation in nursing home residents with and without dementia, Int. Psychogeriatr. 27 (12) (2015) 1945-1955.

[14] H.J. van Alphen, K.M. Volkers, C.G. Blankevoort, E.J. Scherder, T. Hortobagyi, M.J. van Heuvelen, Older adults with dementia are sedentary for most of the day, PLoS One 11 (3) (2016) e0152457.

[15] S.E. Barber, A. Forster, K.M. Birch, Levels and patterns of daily physical activity and sedentary behavior measured objectively in older care home residents in the united kingdom, J. Aging Phys. Act. 23 (1) (2015) 133-143.

[16] N. Reid, E. Eakin, T. Henwood, J.W.L. Keogh, H.E. Senior, P.A. Gardiner, E. Winkler, G.N. Healy, Objectively measured activity patterns among adults in residential aged care, Int. J. Environ. Res. Public Health 10 (12) (2013) 6783-6798.

[17] M.C. Dale, A. Burns, L. Panter, J. Morris, Factors affecting survival of elderly nursing home residents, Int. J. Geriatr. Psychiatry 16 (1) (2001) 70-76.

[18] E.J. Scherder, T. Bogen, L.H. Eggermont, J.P. Hamers, D.F. Swaab, The more physical inactivity, the more agitation in dementia, Int. Psychogeriatr. 22 (8) (2010) 12031208.

[19] W. Moyle, E. Beattie, B. Draper, S. Shum, L. Thalib, C. Jones, S. O'Dwyer, C. Mervin, Effect of an interactive therapeutic robotic animal on engagement, mood states, 
agitation and psychotrophic drug use in people with dementia. A cluster randomised controlled trial protocol, BMJ Open 5 (8) (2015) e009097.

[20] J.T. Rowland, D. Basic, J.E. Storey, D.A. Conforti, The rowland universal dementia assessment scale (rudas) and the folstein mmse in multicultural cohort of elderly persons, Int. Psychogeriatr. 18 (2006) 111-120.

[21] P. Werner, J. Cohen-Mansfield, V. Koroknay, Braun J., The impact of a restraintreduction program on nursing home residents, Geriatric Nursing 15 (3) (1994) 142-146. [22] J. Sansoni, N. Marosszeky, Y.-H. Jeon, L. Chenoweth, G. Hawthorne, M. King, Budge M, Zapart S, Sansoni E, Senior K, Kenny P, Low L, Final report: Dementia outcomes measurement suite project, University of Wollongong, Centre for Health Service Development, Australia, 2007.

[23] J. Murphy, J. Holmes, C. Brooks, Measurements of daily energy intake and total energy expenditure in people with dementia in care homes: The use of wearable technology, J. Nutr. Health Aging (2017) 1-6.

[24] D.C. Mackey, T.M. Manini, D.A. Schoeller, A. Koster, N.W. Glynn, B.H. Goodpaster, S. Satterfield, A.B. Newman, T.B. Harris, S.R. Cummings, for the Health Aging and Body Composition Study, Validation of an armband to measure daily energy expenditure in older adults, J. Gerontol. A Biol. Sci. Med. Sci. 66 (10) (2011) 1108-1113.

[25] K.M. Madden, M.C. Ashe, C. Lockhart, J.M. Chase, Sedentary behavior and sleep efficiency in active community-dwelling older adults, Sleep Science (Sao Paulo, Brazil) 7 (2) (2014) 82-88.

[26] E. Galik, B. Resnick, M. Hammersla, J. Brightwater, Optimizing function and physical activity among nursing home residents with dementia: Testing the impact of function-focused care, Gerontologist 54 (6) (2014) 930-943. 
[27] L. Brett, V. Traynor, P. Stapley, Effects of physical exercise on health and well-being of individuals living with a dementia in nursing homes: A systematic review, J. Am. Med. Dir. Assoc. 17 (2) (2016) 104-116.

[28] National Sleep Foundation, https://sleepfoundation.org/, 2016 (accessed May 18).

[29] J. Ostaszkiewicz, B. O'Connell, T. Dunning, Night-time continence care in australian residential aged care facilities: Findings from a grounded theory study, Contemp. Nurse (2015) 1-11.

[30] E.F. Camargos, F.M. Louzada, O.T. Nóbrega, Wrist actigraphy for measuring sleep in intervention studies with alzheimer's disease patients: Application, usefulness, and challenges, Sleep Med. Rev. 17 (6) (2013) 475-488.

[31] A. Godfrey, Wearables for independent living in older adults: Gaits and falls, Maturitas 100 (2017) 16.

[32] M. Harris, V. Grando, When is nighttime? A description of bedtime in persons with dementia in the nursing home, Geriatr. Nurs. 35 (6) (2014) 474-478.

[33] J.A. Lee, K.R. Laurson, Validity of the sensewear armband step count measure during controlled and free-living conditions, J. Exerc. Sci. Fit. 13 (1) (2015) 16-23. 
Table 1. Characteristics of included residents $(n=192)$

\begin{tabular}{|c|c|}
\hline Characteristic & $n=192$ \\
\hline Sex (female) & $142(74.0 \%)$ \\
\hline Age (years) & $85.5(7.7)$ \\
\hline RUDAS (total score) & $7.9(6.7)$ \\
\hline CMAI-SF (total score)* & $28.9(10.1)$ \\
\hline \multicolumn{2}{|l|}{ Type of dementia diagnosed: } \\
\hline Alzheimer's disease & $63(32.8 \%)$ \\
\hline Vascular dementia & $31(16.1 \%)$ \\
\hline Dementia with Lewy bodies & $3(1.6 \%)$ \\
\hline Fronto temporal lobar degeneration & $2(1.0 \%)$ \\
\hline Alcohol-related dementia & $1(0.5 \%)$ \\
\hline Unspecified & $92(47.9 \%)$ \\
\hline Taking medication (yes): & $147(76.6 \%)$ \\
\hline Antidepressants ${ }^{\mathrm{b}}$ & $83 / 147(56.5 \%)$ \\
\hline Antipsychotics ${ }^{b}$ & $68 / 147(46.3 \%)$ \\
\hline Anxiolytics and hypnotics ${ }^{\mathrm{b}}$ & 49/147 (33.3\%) \\
\hline Anticonvulsants ${ }^{\mathrm{b}}$ & $14 / 147(9.5 \%)$ \\
\hline Analgesics ${ }^{\mathrm{b}}$ & $43 / 147(29.3 \%)$ \\
\hline Anticholinesterase inhibitors ${ }^{\mathrm{b}}$ & 19/147 (12.9\%) \\
\hline \multicolumn{2}{|l|}{ Mobility status: ${ }^{\mathrm{a}}$} \\
\hline Mobile & 64/186 (33.3\%) \\
\hline Mobile with aid & $91 / 186(47.4 \%)$ \\
\hline Not mobile & $31 / 186(16.1 \%)$ \\
\hline Sensory deficit (yes): ${ }^{a}$ & $161 / 188(83.9 \%)$ \\
\hline Hearing & $85 / 161(52.8 \%)$ \\
\hline Vision $^{\mathrm{b}}$ & $138 / 161(85.7 \%)$ \\
\hline Olfaction $^{\mathrm{b}}$ & 2/161 (1.2\%) \\
\hline Touch/Pain/Tingling ${ }^{\mathrm{b}}$ & $24 / 161(14.9 \%)$ \\
\hline Other ${ }^{b}$ & $9 / 161(5.6 \%)$ \\
\hline \multicolumn{2}{|l|}{ Time in facility (years): ${ }^{\mathrm{a}}$} \\
\hline$<1$ & 68/192 (35.4\%) \\
\hline $1-3$ & $92 / 192(47.9 \%)$ \\
\hline $4-6$ & $23 / 192(12.0 \%)$ \\
\hline $7-9$ & 6/192 (3.1\%) \\
\hline$\geq 10$ & $3 / 192(1.6 \%)$ \\
\hline \multicolumn{2}{|l|}{ Facility care-type environment: ${ }^{a}$} \\
\hline Secure dementia unit & $105 / 191(54.7 \%)$ \\
\hline Facility ward/unit & $86 / 191(44.8 \%)$ \\
\hline \multicolumn{2}{|l|}{ Facility room-type environment: } \\
\hline Single room & $160(83.3 \%)$ \\
\hline Shared room & $32(16.7 \%)$ \\
\hline
\end{tabular}

Categorical data are presented as $n$ (\%), with group differences analysed by Pearson's Chi-Square Test or Fisher's Exact Test. Continuous data are presented as mean (standard deviation), with group differences analysed by One-Way ANOVA. RUDAS = The Rowland Universal Dementia Assessment Scale: A Multicultural Cognitive Assessment Scale. CMAI - SF = The Cohen-Mansfield Agitation Inventory - Short Form. ${ }^{a}$ Data not available for all residents. ${ }^{b}$ Multiple response item. Statistically significant difference between included $(\mathrm{n}=192)$ and excluded $(\mathrm{n}=223)$ residents at the level of ${ }^{*} p=0.038$. 
Table 2. Residents' ( $n=192)$ activity and sleep patterns: 24-hours, daytime, and nighttime

\begin{tabular}{lccc}
\hline & $\begin{array}{c}\text { Overall: } \\
\text { 24-hours }\end{array}$ & $\begin{array}{c}\text { Daytime: } \\
\text { 8am - 7:59pm }\end{array}$ & 8pm - 7:59am \\
\hline Step Count (n) & $307.5(803.3) ; 3-8253$ & $240.2(646.7) ; 0-5927$ & $67.2(199.8) ; 0-2326$ \\
Total Energy Expenditure (kjs) & $6594.6(1436.4) ; 3989-11341$ & $3557.4(921.4) ; 1816-6964$ & $3037.2(631.4) ; 2048-5862$ \\
Metabolic Equivalent of Task (MET) & $1.1(0.2) ; 1-2$ & $1.2(0.3) ; 1-2$ & $1.0(0.2) ; 1-2$ \\
Light Physical Activity (hours) & $2.4(2.3) ; 0-10$ & $1.8(1.8) ; 0-9$ & $0.6(0.7) ; 0-4$ \\
Lying Down (hours) & $10.4(4.0) ; 2-24$ & $2.0(2.3) ; 0-12$ & $8.4(2.7) ; 0-12$ \\
Awake (hours) & $15.3(3.8) ; 2-23$ & $10.2(1.8) ; 2-12$ & $5.0(2.9) ; 0-12$ \\
Sleep (total) (hours) & $8.1(3.8) ; 1-21$ & $1.3(1.7) ; 0-9$ & $6.8(2.9) ; 0-12$ \\
$\quad$ Light Sleep (hours) & $6.3(3.0) ; 1-17$ & $1.0(1.4) ; 0-9$ & $5.3(2.3) ; 0-11$ \\
$\quad$ Deep Sleep (hours) & $1.2(1.2) ; 0-5$ & $0.2(0.4) ; 0-2$ & $1.0(1.1) ; 0-5$ \\
Very Deep Sleep (hours) & $0.6(0.8) ; 0-6$ & $0.1(0.2) ; 0-2$ & $0.5(0.7) ; 0-6$ \\
\hline
\end{tabular}

Data are presented as mean (standard deviation); range. Vs = versus; $n=$ number; kjs = kilojoules. ${ }^{a}$ May not add up to $100 \%$ due to missing data or rounding. 


\section{FIGURE LEGENDS}

Figure 1. Mean number of steps taken per hour, over a 24-hour period

Figure 2. Mean time spent in physical activity per hour, over a 24-hour period

Figure 3. Mean time spent awake and asleep per hour, over a 24-hour period 


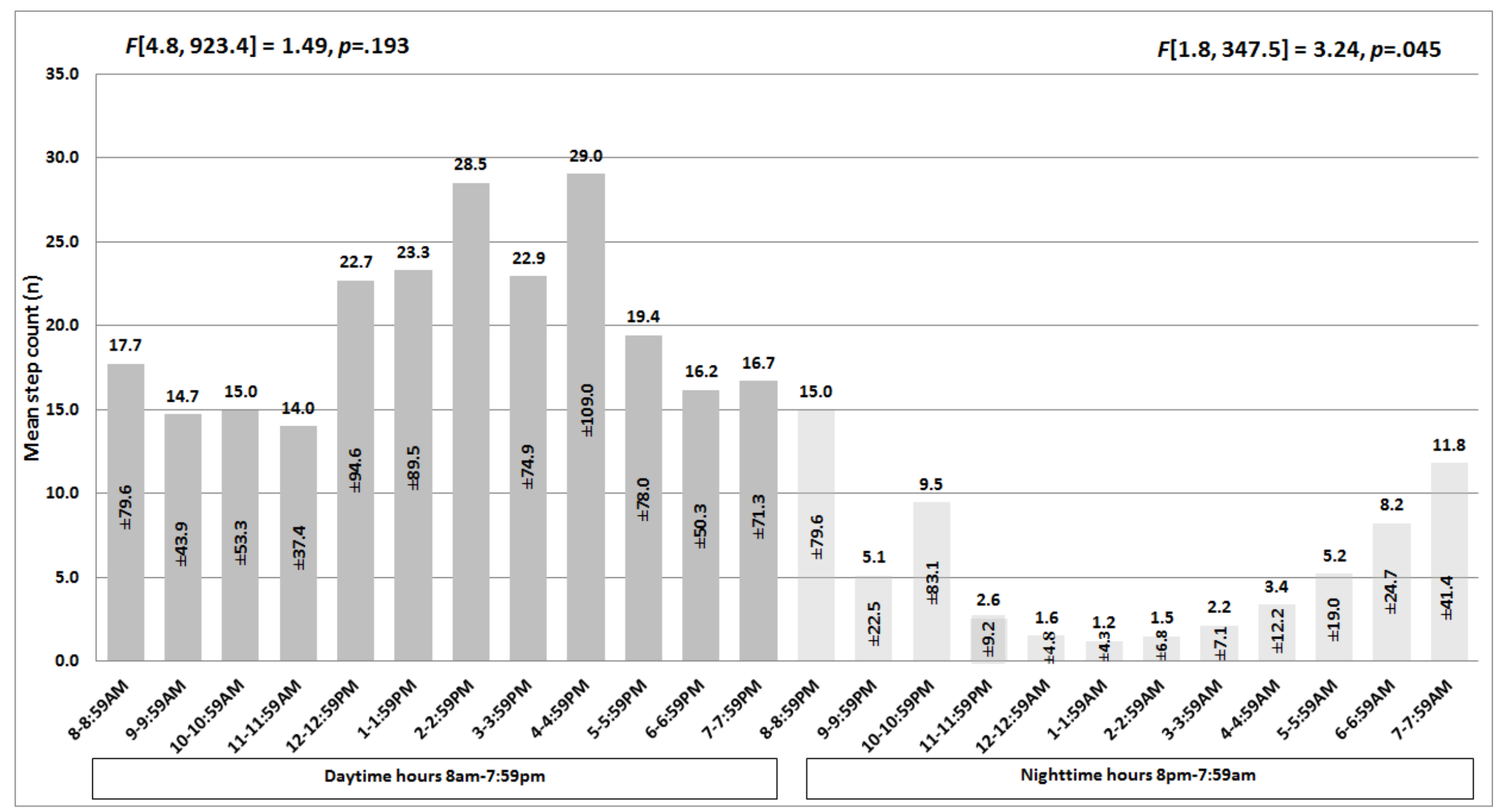




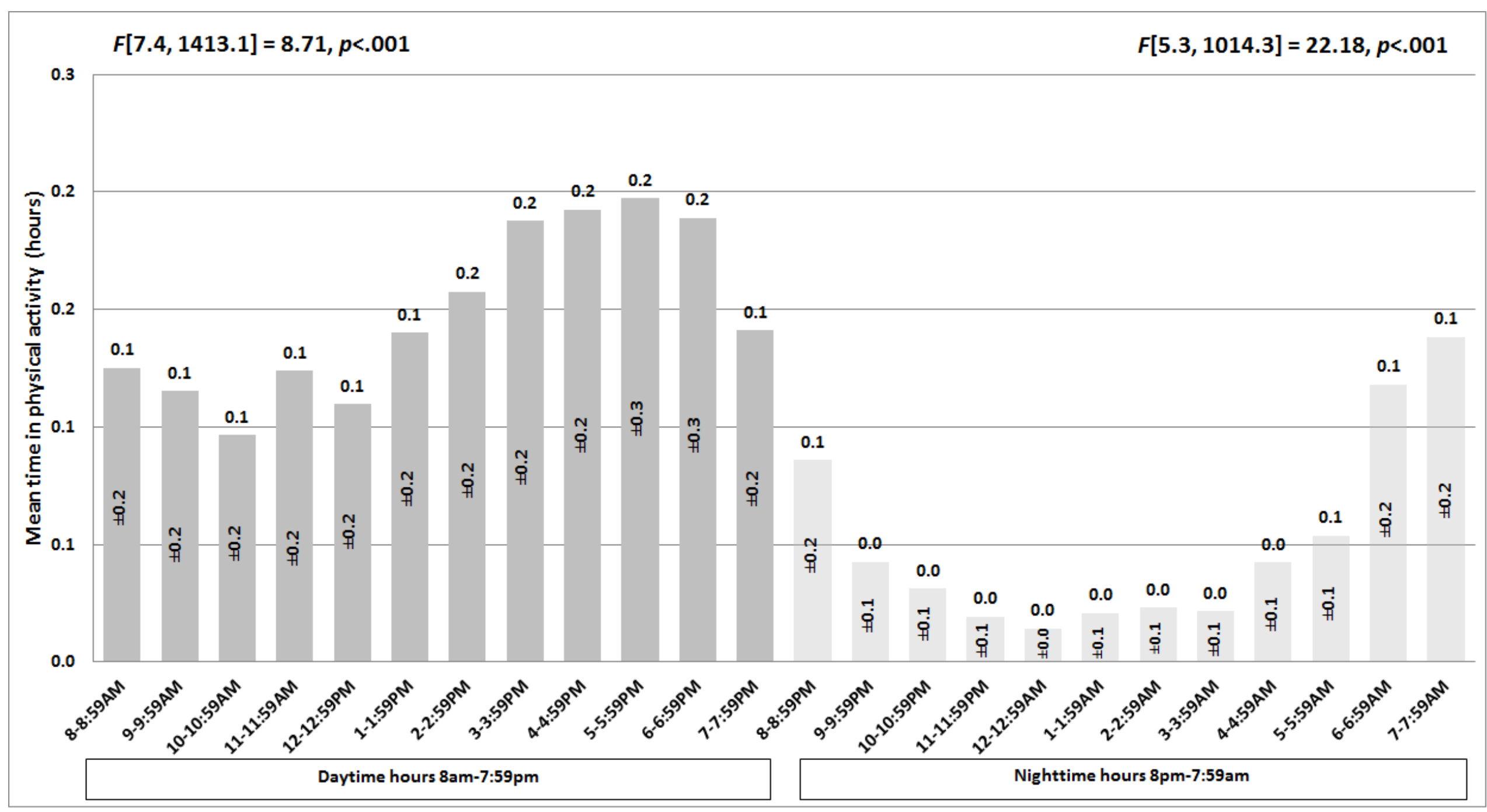




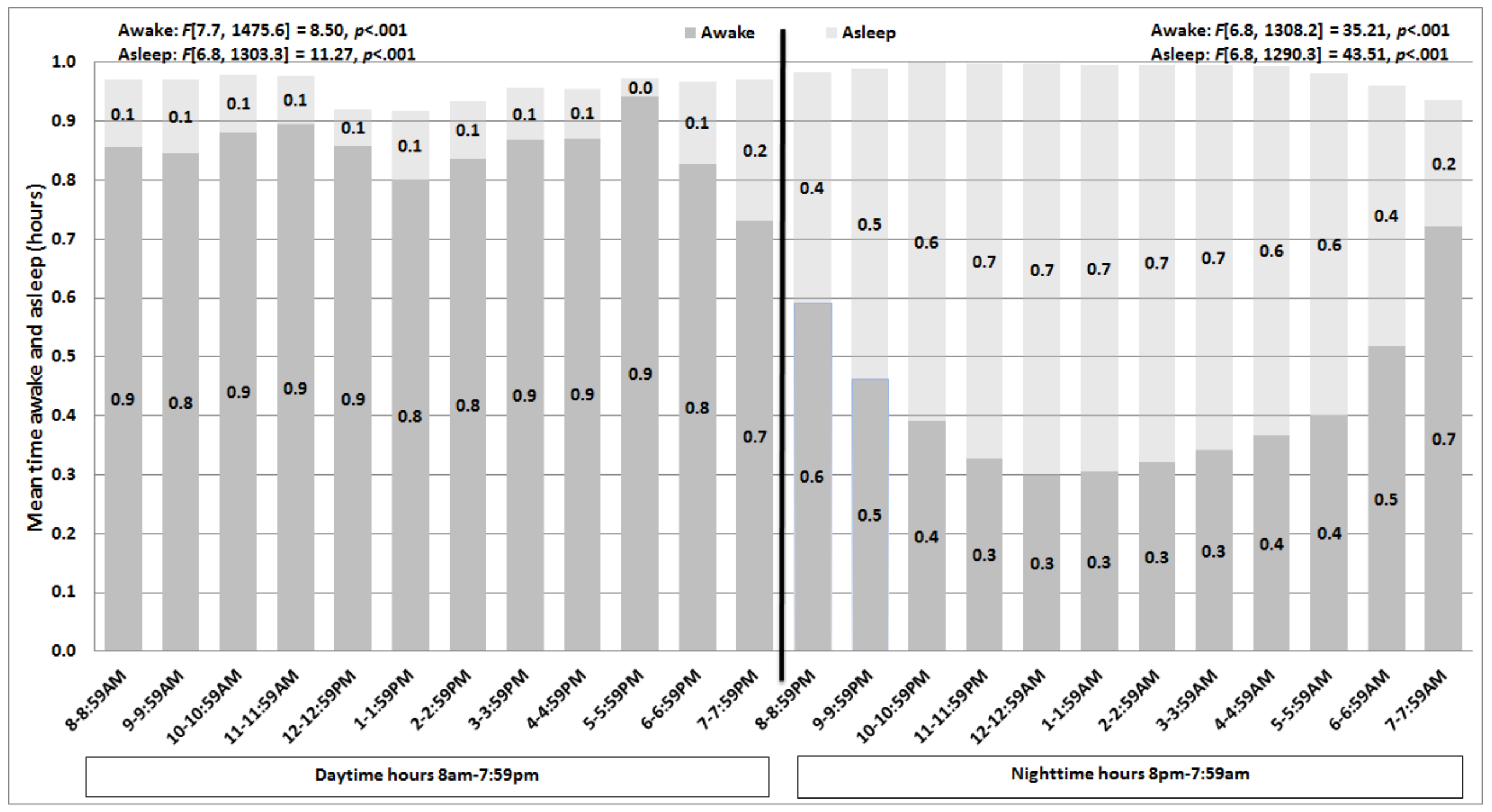

